\title{
5 Analysis of Fault-Related Folding in South of Birjand
}

\author{
Mohammad Khalaj \\ Faculty of Science, Department of Geology, Payame Noor University, Tehran, Iran \\ Email: M khalaj@pnu.ac.ir
}

Received 27 April 2015; accepted 7 June 2015; published 10 June 2015

Copyright (C) 2015 by author and Scientific Research Publishing Inc.

This work is licensed under the Creative Commons Attribution International License (CC BY). http://creativecommons.org/licenses/by/4.0/

(c) (i) Open Access

\begin{abstract}
Folds have a significant development in the Cretaceous-Tertiary rock units of the northern part of Bagheran Mountains in southwest Birjand between Lut and Sistan structural zones. The general trends of fold axis and axial surface are E-W and the folds are less exposed by distance from mountain and plain boundary. Geometric and kinematic status investigation of folds (such as f2 fold in the middle part) and faults shows that faulting process has created some of the folds leading to their development. Such structures are described as fault-related folds. Also, analysis of geometry and mechanism of faults indicate that back thrusts have the largest influence on generation and development of folds in this region.
\end{abstract}

\section{Keywords}

Fault, Fault-Related Fold, Back Thrust, Birjand

\section{Introduction}

The area of study is situated in westernmost end of Bagheran Mountain Range in southwest of Birjand City (40 $\mathrm{km}$ far from Khousf) between the following geographical coordinates: $59^{\circ} 5{ }^{\prime} 50^{\prime \prime} \mathrm{E}-59^{\circ} 11^{\prime} 09^{\prime \prime} \mathrm{E}$ and $32^{\circ} 50^{\prime} 01^{\prime \prime} \mathrm{N}$ $32^{\circ} 50 ' 35 " \mathrm{~N}$. Geologically, this region is located between Lout-Sistan structural zones. As structural trends in Sistan zone in the northwestern part are orientated along E-W direction (Figure 1(a)), the main outcrop trend of rock units and faulted zones in the respective area is E-W. Displacement along vertical component in easternwestern faulted zones has resulted in development of reverse faults in the subzone bounded by the Sistan and Lout zones.

It seems vital to investigate the relationship between folding and faulting in the respective region due to presence of faults with reverse mechanism and influence of faulting activity on development of structures in this region. Folding and thrust faulting is a significant pattern implying that the upper part of continental crust has been 

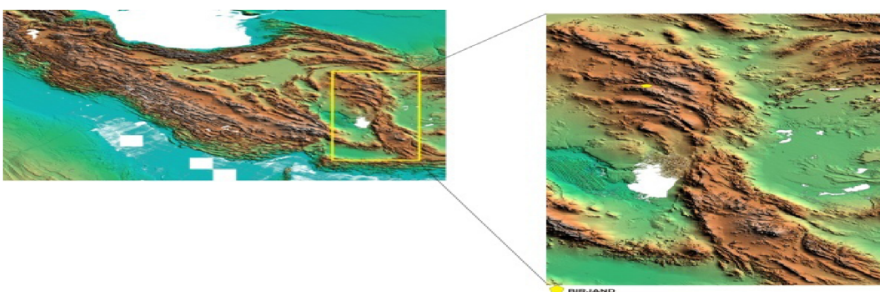

(a)

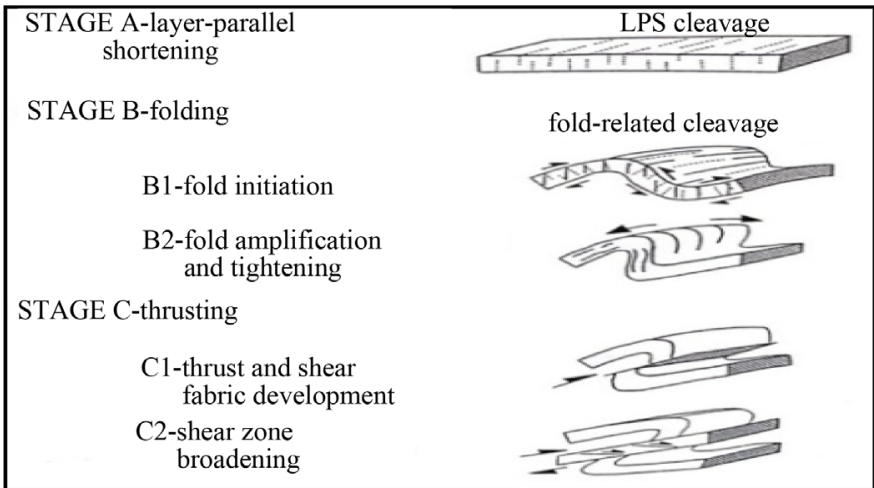

(b)

Figure 1. (a): As shown in the map, exposure of rock units in central Lout area ends to E-W trends; (b): Schematic sequence of wellknown structural stages (A to $\mathrm{C}$ ) and their sub-stages.

formed as a result of horizontal shrinkage or shortening along the orogenic process [1]. Many geologists including Mitra [2] and Jamison [3] studied the genetic association between these two processes along fold-and-thrust belts in their research works. The question regarding these structures is whether the respective structures are geometrically and kinetically associated with each other or not, and also, how they evolve with time. Via investigation of minor structures in fold-and-thrust belt of Ambria-Marci in Italy and Rocky Mountains in Canada along with analysis of their genetic linkage with each other and with major structures, it was revealed that structural evolution of the aforementioned fold-and-thrust belts originates from three processes namely; shortening parallel to bedding, folding, and thrusting. The respective three stages are crucial processes in regions with compressional deformations and also in evolution of fold-and-thrust belts (Figure 1(b)) [1].

Although the schematic representation of structural stages in Figure 1(b) suggests that folding has occurred prior to thrusting but the relationship between the folds and thrusts is not always like this [4]. Fluety classifies the models predicting the relationship between folding and thrusts in two principal groups:

1) Thrust-related Folding.

In this group, folds are formed on the top and at the tip of upward-developing thrusts like fault-bend folds and thrust-tip folds; the latter in turn comprises detachment folds and fault propagation folds [3].

2) Imbricate-generating folds (folding before fault development).

\subsection{Geological and Tectonic Position}

Bagheran Mountain Range is one of the branches of Sistan zone orientated into Lout zone [5]. In this region, kush units (sand + shale + phyllite) have been pushed over pEs units (sandy limestone + phyllite shale) by a reverse faulting. Another reverse fault has caused thrusting of mtsp units (metamorphosed splitic rocks) onto kush units. Reverse faulting has led to exposure of oceanic floor sequence units such as peridotites (pd) on ground surface [6] (Figure 2). It can be therefore asserted that surface exposure of peridotites by itself is reflective of thrust fault front and corroborates a compressional displacement in the region.

\subsection{Geometric-Kinetic Analysis of Structural Elements}

f1: The axial plane of this fold has a N70W strike and 86SW dip and its axis has a trend of N110, 17 (Figure 
3(b)). According to Fleuty classification [7] the axial plane inclination of this structure suggests an upright fold and it is classified as a gently plunging fold based on its axis plunge. This fold has occurred in sandstone units. As observed in the restored image (Figure 3(a)), the rock units were initially folded, then the thrust fault (F1) displaced the folded layers southwards, and finally, the second thrust (F2) occurred displacing the layers southwards with smaller displacement compared to the primary thrusting. Taking into account the northeastern direction of the thrust plane, these thrusts are introduced as back thrusts of the major faults of the region. The associated folds have occurred prior to thrusting and this result is consistent with the model proposed by [1].

f2: This folding is of fault-bend fold category. The inter-limb angle is 130 and the dip angle of terrace is $30^{\circ}$. The measured values are plotted on Jamison's diagram [3]. The acquired point lies on uniform bed thickness curve (Figure 4). It can be therefore stated that no thickness variation has occurred in limbs during folding event (Figure 4). Also, the geometrical attitude of the fault is N65W, 30NE. This fault can be regarded as a back thrust based on its dip direction. The respective folding was sampled in sandstone units.

f3: This fold was sampled in phyllite units (Figure 5). The attitude of its axial plane is N85W, 60NE and its axis has an orientation of N291, 25. According to Fleuty's classification [8], this structure represents a steeply inclined fold based on dip angle of its axial plane and is categorized as a gently plunging fold based on the plunge of its axis. This fold is a minor one exhibiting s-shape geometry. The minor folds are seen in three forms i.e. "s", "m" and "z" within a major fold. The axes and axial planes of the minor folds are parallel to those of the major fold [7].

f4: The attitude of axial plane of this fold is N63W, 46NE and its axis has an orientation of N110, 15. It is a gently plunging fold based on plunge of its axis. A fault with an attitude of N70W, 50NE has created this fold within radiolarite units (Figure 6).
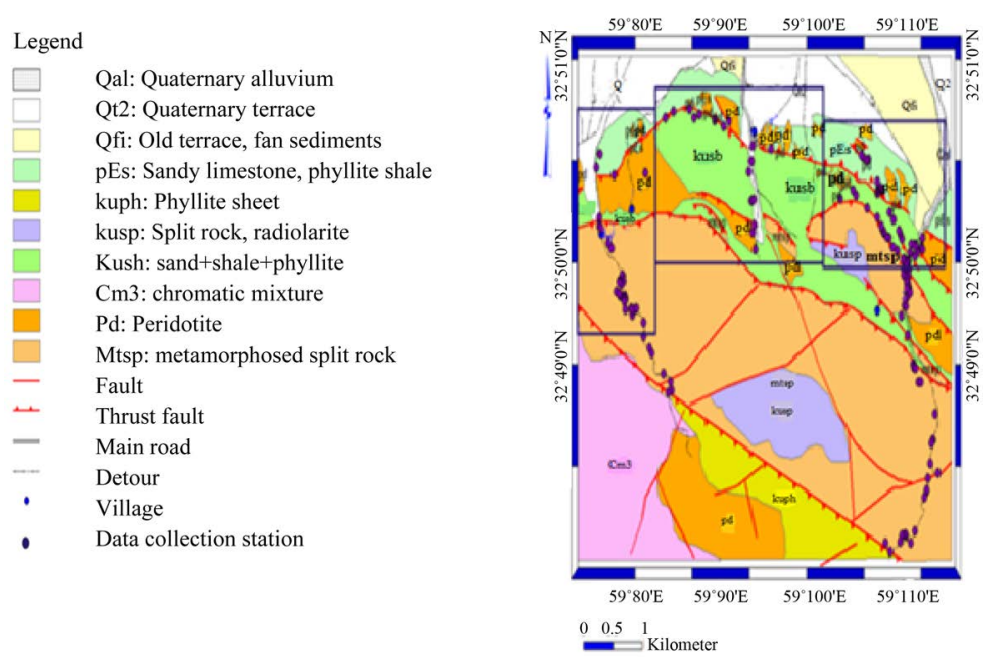

Figure 2. Geological map of the area of study. \{From left to right on map: Western part, Middle part, Eastern part\}.

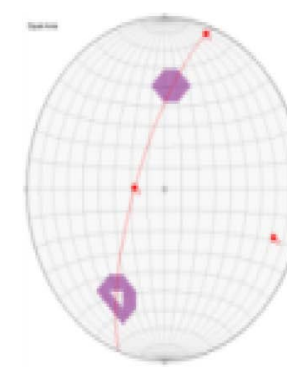

(a)

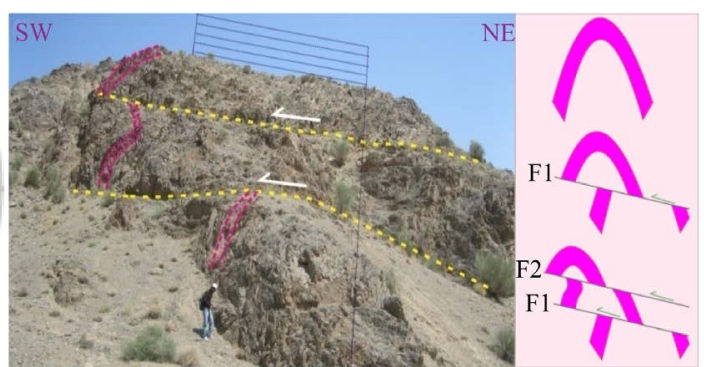

(b)

Figure 3. (a) Schematic representation of faulting stages of f1 fold limbs. (b) Folding in rock units together with pole diagram of fold limbs and representation of stress axes orientation. 


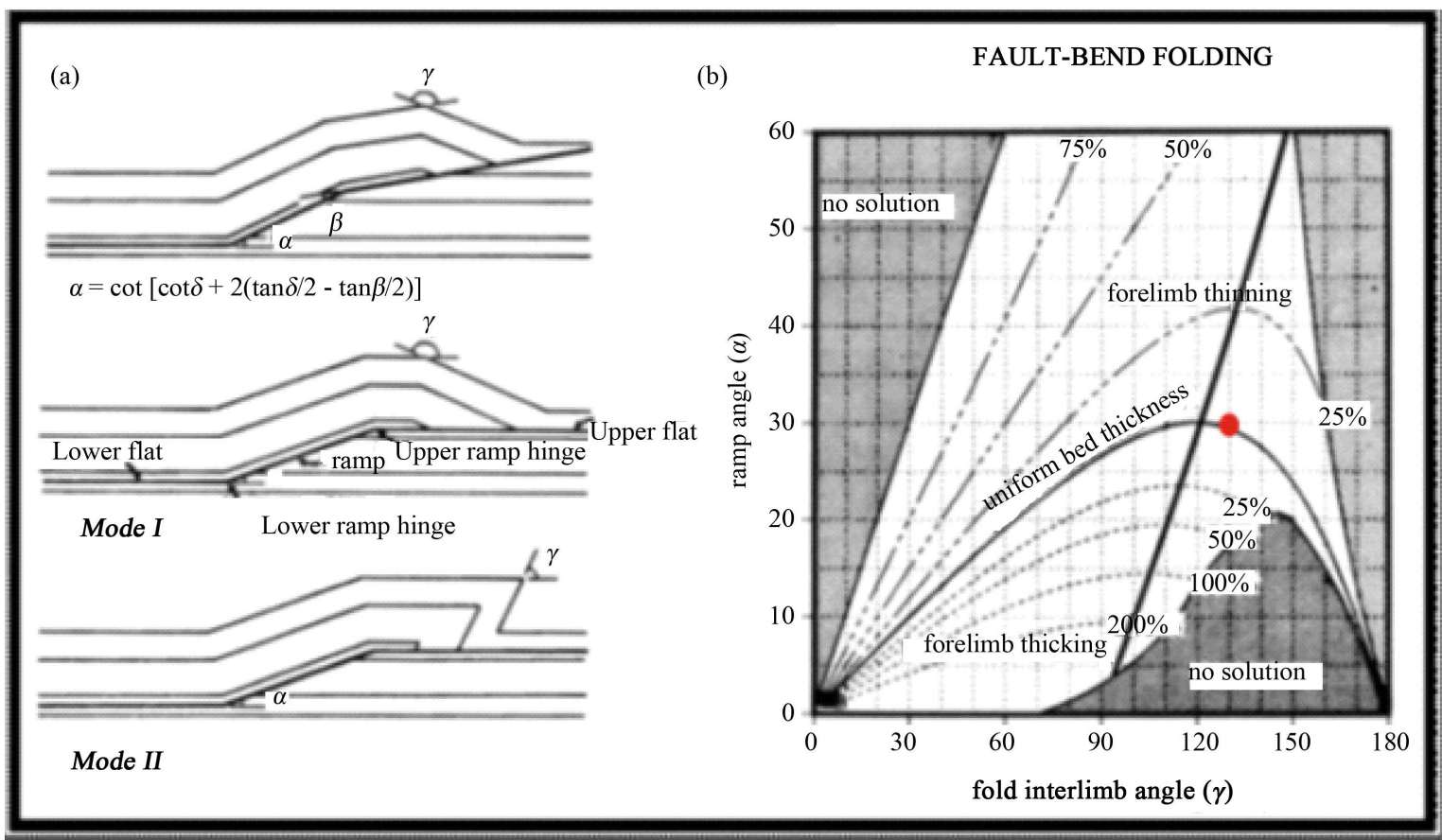

Figure 4. (a) Thickening and thinning diagram of front limb for fault-bend folds (measurement of terrace dip $(\alpha)$ and inter-limb angle for fault-bend folds (v)) [from Jamison (1987)].
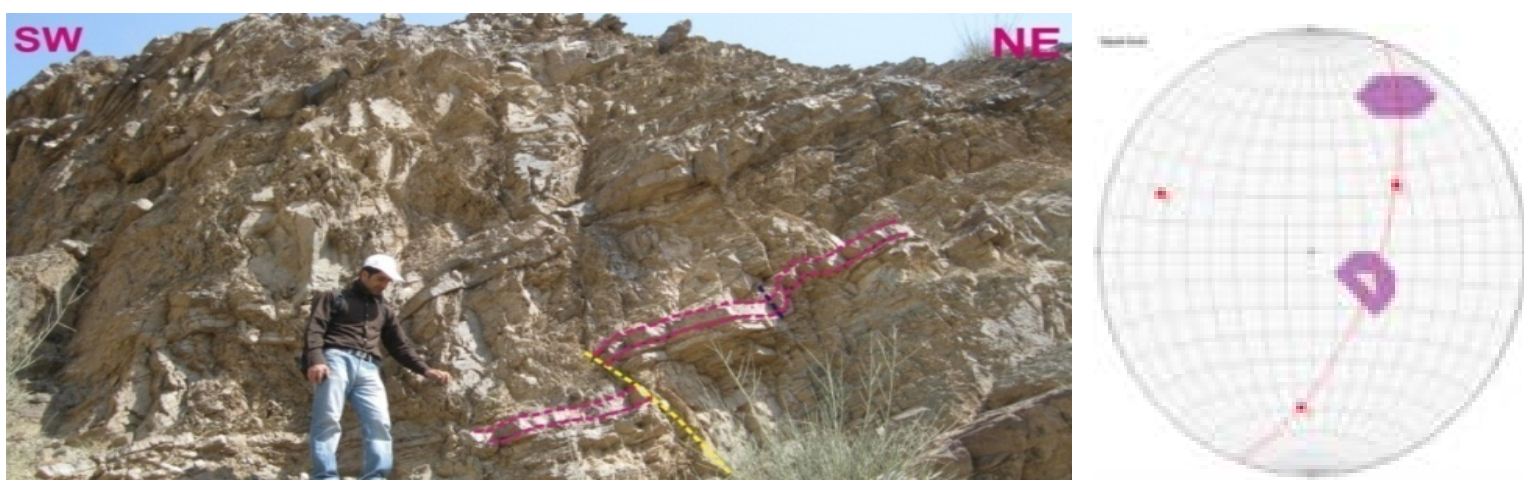

Figure 5. Folding in rock units together with pole diagram of fold limbs and representation of stress axes orientation.

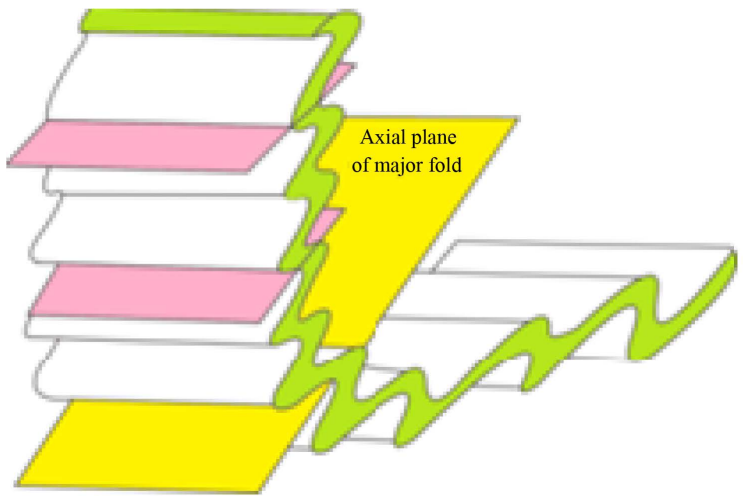

(a)

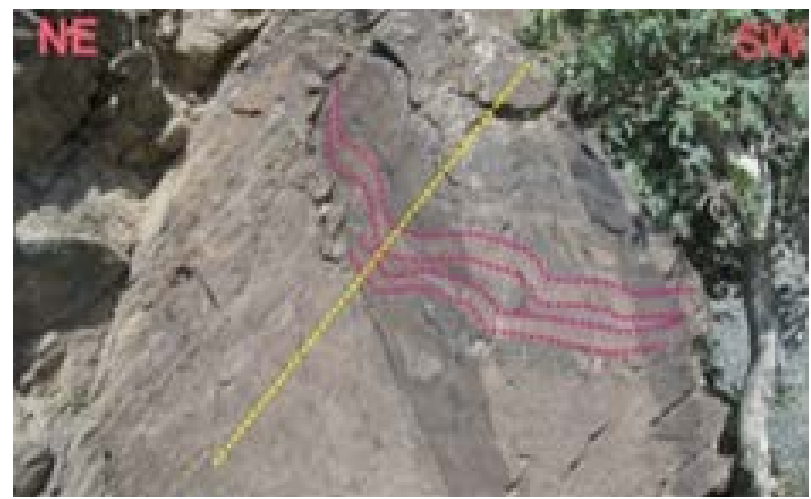

(b)

Figure 6. (a) minor folds in $\mathrm{f} 4 \mathrm{fold}$; the yellow line represents dip direction of axial plane; (b). geometrical relationship between major fold and minor folds; axes and axial planes of minor folds are parallel to those of major fold (Price, 1990). 


\section{Conclusions}

The investigations indicate that the relationship between folding and faulting in the region can be divided into two major categories. In the first category, faulting process has caused folding of rock units, which are mainly of fault-bend type (such as f1 fold). In the second category, folding process has occurred before faulting (e.g. f2 fold), which is in accordance with the model proposed by [1]. The geometry of faults demonstrates that back thrusts have played a substantial role in development of folds in the first group as well as displacement of layers in the second group.

\section{References}

[1] Tavarnelli, E. (1997) Structural Evolution of a Foreland Fold-and-Thrust Belt: The Umbria-Marche Apennines, Italy. Journal of Structural Geology, 19, 523-534. http://dx.doi.org/10.1016/S0191-8141(96)00093-4

[2] Mitra, S. (2002) Structural Models of Faulted Detachment Folds. AAPG Bulletin, 86, 1673-1694.

[3] Jamison, W.R. (1987) Geometric Analysis of Fold Development in Overthrust Terrains. Journal of Structural Geology, 9, 207-219. http://dx.doi.org/10.1016/0191-8141(87)90026-5

[4] Morley, C.K. (1994) Fold-Generated Imbricates: Examples from the Caledonides of Southern Norway. Journal of Structural Geology, 16, 619-631. http://dx.doi.org/10.1016/0191-8141(94)90114-7

[5] Ali, A. (2004) Iran’s Geology. Iran’s Geological Survey and Mineral Explorations Publications, Me’radj Blvd, Tehran, Iran, 586.

[6] Eftekharnezhad, J. (1986) 1:100000 Geological Map of Birjand. Iran’s Geological Survey and Mineral Explorations Publications, Me'radj Blvd, Tehran, Iran.

[7] Price, N.J. and Cosgrove, J.W. (1990) Analysis of Geological Structures. Cambridge University Press, Cambridge, 502 p.

[8] Fluety, M.J. (1964) The Description of Folds. Proceedings of the Geologist' Association, 75, 461-492. http://dx.doi.org/10.1016/S0016-7878(64)80023-7 